\title{
An Efficient, Versatile, and Safe Access to Supported Metallic Nanoparticles on Porous Silicon with Ionic Liquids
}

\author{
Walid Darwich ${ }^{1}$, Paul-Henri Haumesser ${ }^{2,3}{ }^{*}$, Catherine C. Santini ${ }^{1}$ and Frédéric Gaillard ${ }^{2,3}$ \\ 1 CNRS-Université de Lyon-ESCPE Lyon, UMR 5265 C2P2, 43 Bd du 11 Novembre 1918, Villeurbanne 69616, \\ France; darwich.walid@hotmail.com (W.D.); catherine.santini@univ-lyon1.fr (C.C.S.) \\ 2 CEA, LETI, MINATEC Campus, Grenoble 38054, France \\ 3 Université Grenoble Alpes, Grenoble 38000, France; frederic-x.gaillard@cea.fr \\ * Correspondence: paul.haumesser@cea.fr; Tel.: +33-4-3878-5759; Fax: +33-4-3878-3034
}

Academic Editors: Andreas Taubert and Peter Hesemann

Received: 30 March 2016; Accepted: 24 May 2016; Published: 3 June 2016

\begin{abstract}
The metallization of porous silicon (PSi) is generally realized through physical vapor deposition (PVD) or electrochemical processes using aqueous solutions. The former uses a strong vacuum and does not allow for a conformal deposition into the pores. In the latter, the water used as solvent causes oxidation of the silicon during the reduction of the salt precursors. Moreover, as PSi is hydrophobic, the metal penetration into the pores is restricted to the near-surface region. Using a solution of organometallic (OM) precursors in ionic liquid (IL), we have developed an easy and efficient way to fully metallize the pores throughout the several- $\mu \mathrm{m}$-thick porous $\mathrm{Si}$. This process affords supported metallic nanoparticles characterized by a narrow size distribution. This process is demonstrated for different metals $(\mathrm{Pt}, \mathrm{Pd}, \mathrm{Cu}$, and $\mathrm{Ru})$ and can probably be extended to other metals. Moreover, as no reducing agent is necessary (the decomposition in an argon atmosphere at $50{ }^{\circ} \mathrm{C}$ is fostered by surface silicon hydride groups borne by $\mathrm{PSi}$ ), the safety and the cost of the process are improved.
\end{abstract}

Keywords: porous silicon; metallization; surface reactivity; metallic nanoparticles

\section{Introduction}

Porous silicon (PSi) has been attracting a great amount of attention as a breakthrough material with exceptional characteristics for microelectronics, integrated optoelectronics, microelectromechanical systems (MEMS), layer transfer technology, solar and fuel cells, biomedicine, etc. [1,2]. Depending on the conditions for its elaboration, PSi can exhibit a wide range of morphological properties, from extremely small pores below $5 \mathrm{~nm}$ (microporous) to micrometric pores (macroporous). Moreover, its high surface area (microporous silicon $\sim 1000 \mathrm{~m}^{2} / \mathrm{cm}^{3}$, mesoporous silicon $\sim 100 \mathrm{~m}^{2} / \mathrm{cm}^{3}$, macroporous silicon $\sim 1 \mathrm{~m}^{2} / \mathrm{cm}^{3}$ ) makes it suitable to host one or more guest materials which usually results in a drastic change of its physical properties [2]. For instance, the addition of a well-chosen metal can provide specific composite structures with new electrical, optical, magnetic, plasmonic, or other properties [3]. In particular, the introduction of $\mathrm{Cu}$ improves the optoelectronic functions of PSi, e.g., its photoluminescence and electroluminescence [4].

The metal can be incorporated by electrochemical or electroless methods, but also by physical evaporation. However, upon evaporation or sputtering, metal atoms remain localized at the entrance of pores [3]. By contrast, immersion methods enhance the penetration of metal atoms deeper into the porous layer [5,6].

Importantly, PSi can reduce many metal ions down to their elemental state. This is due to the presence of $\mathrm{SiH}_{\mathrm{x}}$ bonds formed during the electrolytic synthesis of the material. This can in principle 
enable the deposition of various noble and coinage metals in the porous layer by a chemical surface reaction [7-11].

In aqueous solutions, the source of electrons needed to reduce z-charged metal ions is PSi itself [12].

$$
4 \mathrm{M}^{\mathrm{z}+}+\mathrm{zSi}+2 \mathrm{zH}_{2} \mathrm{O} \rightarrow 4 \mathrm{M}+\mathrm{zSiO}_{2}+4 \mathrm{zH}^{+}
$$

However, the hydrophobic inner pore walls are impermeable to water contributing to concentrate metal deposits on the surface in patches rather than as a conformal layer down into the pores $[7,8,12,13]$.

Nevertheless, this approach remains attractive and elegant, as it could provide an easy, low-cost, and versatile process to metallize PSi. Hence, the purpose of this study is to identify a liquid medium:

1. Capable of penetrating the diverse porous structures [14];

2. in which different metal precursors are soluble $[15,16]$;

3. that does not prevent the reaction of these precursors with surface hydrides [17];

4. and in which additional reagents can be added to extend metal precursor decomposition $[15,18]$.

We believe that ionic liquids (ILs) fulfill all these requirements. Indeed, ILs are suitable media to solubilize a wide range of metal precursors. From these solutions, zero-valent metallic nanoparticles (NPs) are easily precipitated using appropriate reducing agents such as $\mathrm{H}_{2}$ [19-22]. Moreover, ILs penetrate quite rapidly in porous materials [14]. Therefore, we investigate in this work the ability of imidazolium-based ILs containing organometallic (OM) precursors to metallize a variety of micro- to macro-porous silicon substrates.

\section{Results and Discussion}

\subsection{Surface Chemistry of PSi Substrates}

Two different porous Si materials were electrochemically etched in p-doped Si wafers (resistivity of 1500 Ohm.cm): macroporous Si (MPSi) and microporous Si ( $\mu \mathrm{PSi})$. Their morphological characteristics are listed in Table 1. Note that, within the macropores of MPSi, portions of the internal surface are microporous. Samples of bulk $\mathrm{Si}$ (BSi) were considered as a reference throughout this study.

Table 1. Samples used in this study.

\begin{tabular}{ccc}
\hline \multirow{2}{*}{ Material } & \multicolumn{2}{c}{ Porous Layer } \\
\cline { 2 - 3 } & Pore Diameter & Thickness \\
\hline Macroporous Si (MPSi) & $5 \mu \mathrm{m}(+5 \mathrm{~nm})$ & $20 \mu \mathrm{m}$ \\
Microporous Si $(\mu \mathrm{PSi})$ & $5 \mathrm{~nm}$ & $2 \mu \mathrm{m}$ \\
\hline
\end{tabular}

Before use, these substrates were dried in a strong vacuum $\left(10^{-5}\right.$ bar, overnight $)$ and stored in a glove box in an argon atmosphere. Diffuse reflectance infra-red Fourier transform analysis (DRIFT) was used to characterize the surface chemical groups of these various substrates (Figure 1).

For all the samples, the peaks at 1100 and at $3500 \mathrm{~cm}^{-1}$ were assigned to $v(\equiv \mathrm{Si}-\mathrm{O}-\mathrm{Si} \equiv)$ and $v(\equiv \mathrm{Si}-\mathrm{OH})$ vibrations, respectively. The peaks at 2134, 2111, 2086, and $2254 \mathrm{~cm}^{-1}$ were attributed to $v\left(\mathrm{SiSiH}_{3}\right), v\left(\mathrm{Si}_{2} \mathrm{SiH}_{2}\right), v\left(\mathrm{Si}_{3} \mathrm{SiH}\right)$, and $v\left(\mathrm{O}_{3} \mathrm{SiH}\right)$ vibrations, respectively. The latter peaks were not detected in BSi and exhibited a much lower intensity in MPSi as compared to $\mu$ PSi. This difference of surface silicon hydride concentration between the two porous materials was confirmed by temperature-programmed desorption experiments performed between 100 and $900^{\circ} \mathrm{C}$. A total of $0.628 \mathrm{mmol} \cdot \mathrm{g}^{-1}$ of $\mathrm{H}_{2}$ was released by $\mu$ PSi vs. $0.055 \mathrm{mmol} \cdot \mathrm{g}^{-1}$ of $\mathrm{H}_{2}$ for MPSi [23]. 


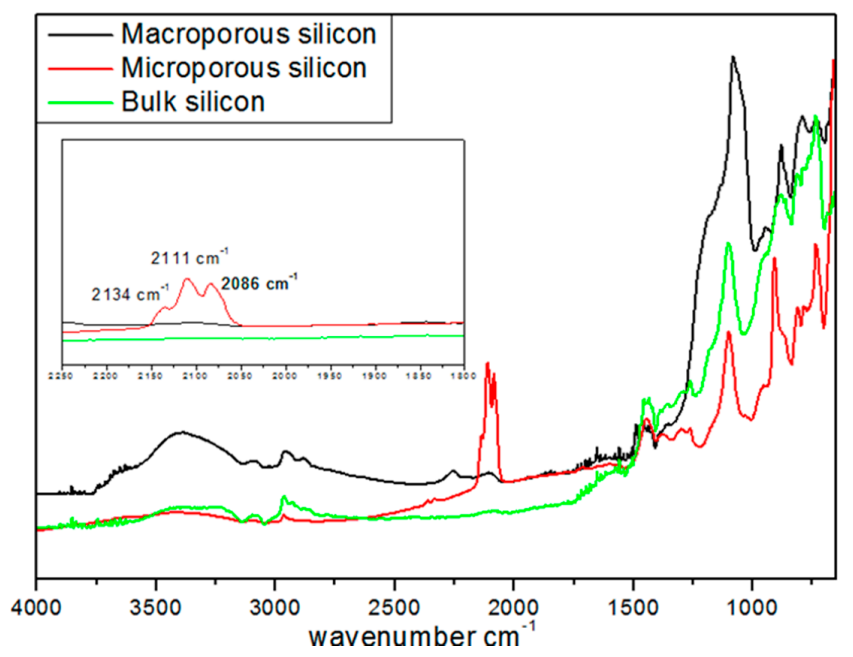

Figure 1. DRIFT spectra of macroporous $\mathrm{Si}(\mathrm{MPSi})$, microporous $\mathrm{Si}(\mu \mathrm{PSi})$, and bulk $\mathrm{Si}(\mathrm{BSi})$ samples in an argon atmosphere at $50{ }^{\circ} \mathrm{C}$.

\subsection{Metallization of PSi}

\subsubsection{Metallization from a Suspension of Metallic NPs in IL}

Suspensions of well-dispersed crystalline metallic zero-valent $\mathrm{Cu}-\mathrm{NPs}$ of $5 \mathrm{~nm}$ with a narrow size distribution were routinely synthesized from the reduction of mesitylcopper (CuMes) in 1-butyl-3-methylimidazolium bis(trifluoromethylsulphonyl)imide $\left[\mathrm{C}_{1} \mathrm{C}_{4} \mathrm{Im}\right]\left[\mathrm{NTf}_{2}\right]$ [24]. These stable $\mathrm{Cu}-\mathrm{NP}$ suspensions could be promising starting materials to achieve conformal copper deposition into PSi layers.

BSi and PSi substrates were impregnated with a suspension of $5 \mathrm{~nm} \mathrm{Cu}-\mathrm{NPs}$ in $\left[\mathrm{C}_{1} \mathrm{C}_{4} \mathrm{Im}\right]\left[\mathrm{NTf}_{2}\right]$ in an argon atmosphere for $2 \mathrm{~h}$ at $50^{\circ} \mathrm{C}$, an $e x$-situ procedure. After treatment, the samples were rinsed with $\mathrm{CH}_{2} \mathrm{Cl}_{2}$. No $\mathrm{Cu}$ deposition was observed on the BSi surface (Figure 2a). This indicates that surface silanol $\equiv \mathrm{Si}-\mathrm{OH}$ are inefficient for the grafting of $\mathrm{Cu}-\mathrm{NPs}$. The metal was washed away via rinsing with $\mathrm{CH}_{2} \mathrm{Cl}_{2}$ and subsequently dried. By contrast, MPSi and $\mu \mathrm{PSi}$ samples exhibited large $\mathrm{Cu}$ aggregates with a broad size distribution on their surface (Figures $2 b$ and $3 a$ ). Such a morphology could result from the agglomeration of the weakly adherent $\mathrm{Cu}-\mathrm{NPs}$ during the rinsing and drying processes [25]. This could mean that surface hydrides are needed to graft $\mathrm{Cu}-\mathrm{NPs}$. This could also be related to the rougher topography of these substrates. Nevertheless, no $\mathrm{Cu}$ was detected in their pores (Figure $3 b$ ). This can be expected in $\mu \mathrm{PSi}$ (the pores have the same size as the NPs), but is more surprising for MPSi. Finally, this procedure proves not to be efficient to metallize the internal surface of the pores [23].

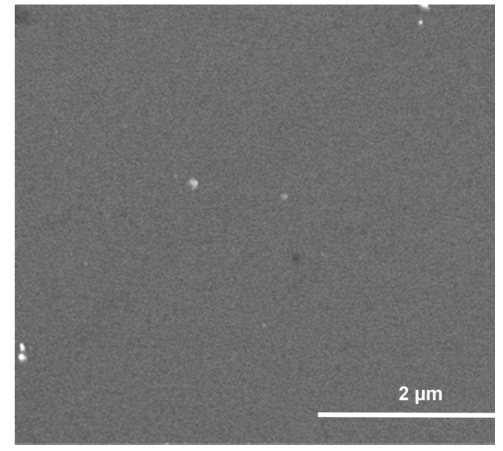

(a)

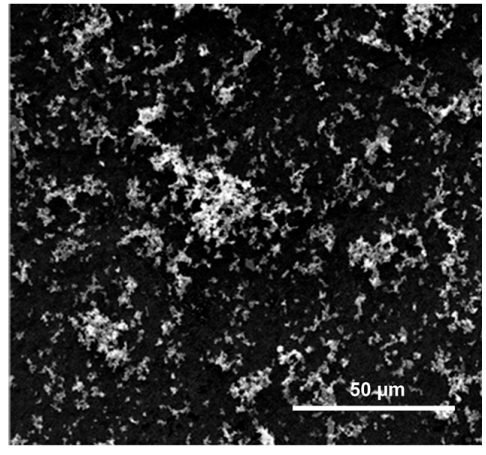

(b)

Figure 2. Surface of (a) BSi and (b) $\mu$ PSi samples after treatment through the ex-situ procedure. 


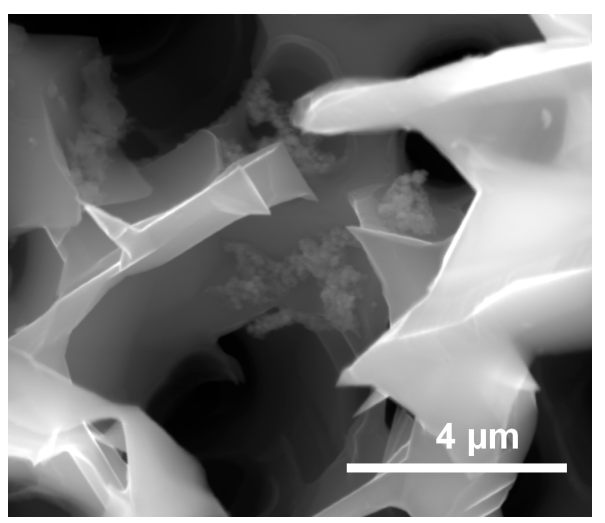

(a)

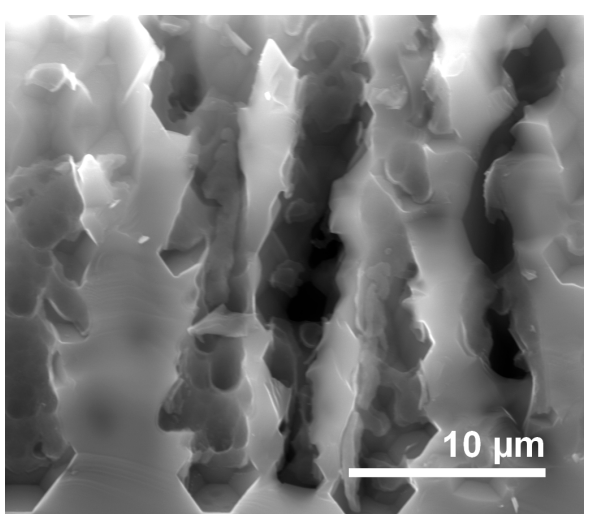

(b)

Figure 3. MPSi sample tentatively metallized through the $e x$-situ procedure. (a) $\mathrm{Cu}$ aggregates are visible on the surface; (b) but not in the pores.

\subsubsection{Metallization from a Solution of CuMes in IL}

In the first experiment, a MPSi substrate was placed in an autoclave and impregnated by a solution of CuMes in $\left[\mathrm{C}_{1} \mathrm{C}_{4} \mathrm{Im}\right]\left[\mathrm{NTf}_{2}\right]$ under argon atmosphere for $2 \mathrm{~h}$ at $50^{\circ} \mathrm{C}$. The autoclave was then placed under $0.9 \mathrm{MPa} \mathrm{H}_{2}$, for $4 \mathrm{~h}$ at $100{ }^{\circ} \mathrm{C}$. Interestingly enough, this procedure afforded $\mathrm{Cu}$ islands, both at the surface and in the pores, after a rinsing process (Figure 4a). Electron dispersive $\mathrm{X}$-ray analysis (EDX) mapping (Figure $4 \mathrm{~b}$ ) confirms that $\mathrm{Cu}$ is coating the inner walls of the macropores. The highest $\mathrm{Cu}$ concentration was detected at the pore walls near the cross-section plane (red). A closer examination of the morphology of the $\mathrm{Cu}$ deposit shows that it was formed of large $(>150 \mathrm{~nm}) \mathrm{Cu}$ islands on the flat walls of the pores and smaller ones (about $12 \mathrm{~nm}$ ) on the microporous walls of macropores (Figure 4c). This could be related to the difference in roughness (rougher surfaces induce more nucleation) or to the increased concentration of surface silicon hydride specifically in the micropores.

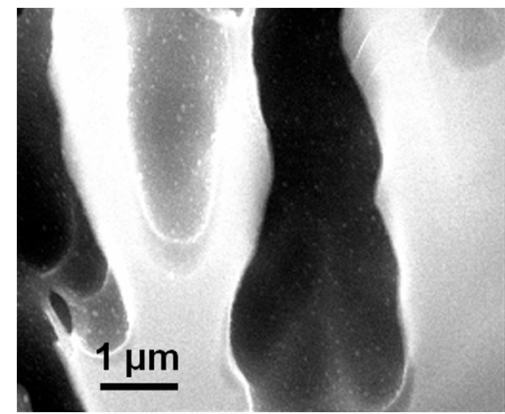

(a)

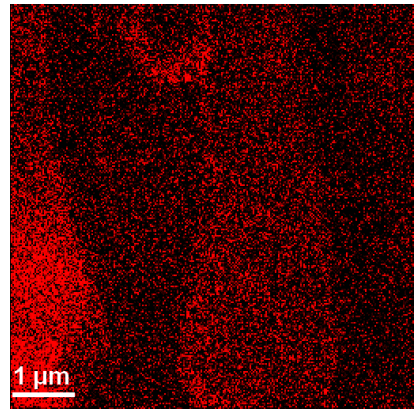

(b)

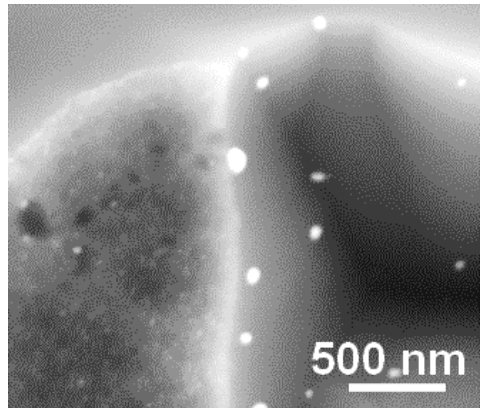

(c)

Figure 4. MPSi sample metallized by decomposing CuMes in $\left[\mathrm{C}_{1} \mathrm{C}_{4} \mathrm{Im}\right]\left[\mathrm{NTf}_{2}\right]$. (a) $\mathrm{Cu}$ islands are clearly visible in the pores; as confirmed by (b) EDX mapping of $\mathrm{Cu}$; (c) $\mathrm{Cu}$ is detected within the hollow macropores. The highest $\mathrm{Cu}$ concentration was detected at the pore walls near the cross-section plane.

In an attempt to increase metal content in the MPSi layer, similar experiments were performed at higher temperatures $\left(150\right.$ and $200^{\circ} \mathrm{C}$ ). The back-scattered electron (BSED) scanning electron microscopy (SEM) images in Figure 5 show that, upon increasing temperature to $150{ }^{\circ} \mathrm{C}$, more $\mathrm{Cu}$ was indeed detected throughout the porous material. At $200{ }^{\circ} \mathrm{C}$, however, $\mathrm{Cu}$ was preferentially deposited near the surface, blocking access to the pores below. The reaction was probably too fast and did not allow for the diffusion of CuMes down to the bottom of the porous layer. 
$100^{\circ} \mathrm{C}$

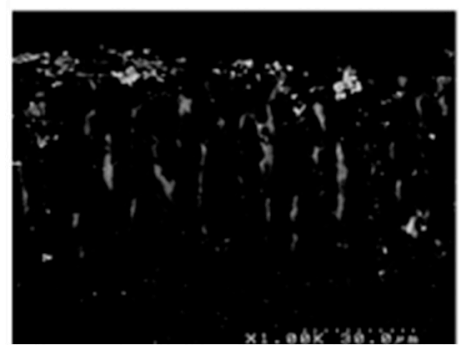

$150^{\circ} \mathrm{C}$

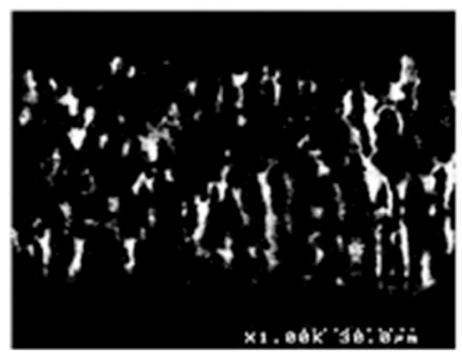

$200^{\circ} \mathrm{C}$

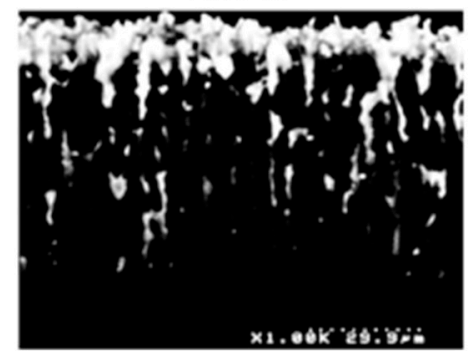

Figure 5. MPSi samples metallized by decomposition of a solution of CuMes in IL at 100, 150 and $200{ }^{\circ} \mathrm{C}$ observed using the back-scattered electron detector (BSED) of the SEM.

Finally, MPSi is a complex material which incorporates planar surface portions as well as micropores. These different surfaces bear different amounts of surface silanol and hybride groups, which are probably involved in either the NP formation or their grafting. To separate these factors, two reference silicon samples can be considered: BSi, which exhibits no porosity and only silanol surface groups (Figure 1), and $\mu \mathrm{PSi}$, containing only micropores in which surface silicon hydride groups dominate. Moreover, the latter material is best suited to the spontaneous $\mathrm{Cu}$ deposition upon immersion in solutions containing cupric ions because of its reductive character [5,26-28].

In order to verify if this reactivity of $\mu \mathrm{PSi}$ still holds in IL-based solutions, the metallization of $\mu \mathrm{PSi}$ and $\mathrm{BSi}$ was attempted by sole impregnation with a solution of CuMes in $\left[\mathrm{C}_{1} \mathrm{C}_{4} \operatorname{Im}\right]\left[\mathrm{NTf}_{2}\right]$ under argon atmosphere for $2 \mathrm{~h}$ at $50{ }^{\circ} \mathrm{C}$. Interestingly enough, after rinsing with $\mathrm{CH}_{2} \mathrm{Cl}_{2}$, an almost closed $\mathrm{Cu}$ film remained on the $\mu \mathrm{PSi}$ surface (Figure $6 \mathrm{~b}$ ). Even more interestingly, $\mathrm{Cu}$ islands with a diameter of about $10 \mathrm{~nm}$ also coated the inner surface of the pores (Figure 6c). Hence, CuMes is indeed readily decomposed by $\mu \mathrm{PSi}$. In contrast, no $\mathrm{Cu}$ deposit remained at the surface of BSi (Figure 6a). This rules out the oxidation of $\mathrm{Si}$ as the second half-reaction responsible for metal deposition in water. Furthermore, these results indicate that the surface hydride groups decompose the $\mathrm{Cu}$ precursor and anchor the Cu-NPs. This would explain why different sizes and surface coverage of $\mathrm{Cu}$ islands are observed in the flat vs. microporous internal surfaces of MPSi. In conclusion, this easy procedure allows for the metallization by $\mathrm{Cu}$ of a variety of porous $\mathrm{Si}$ samples without $\mathrm{H}_{2}$ [23].

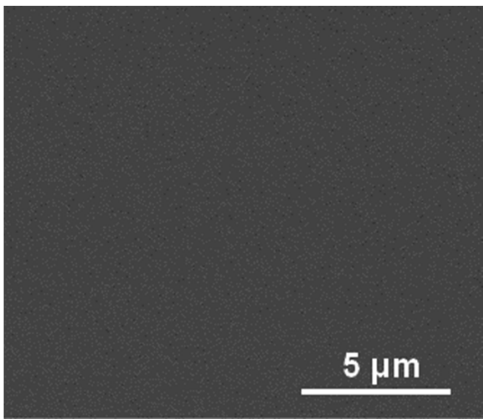

(a)

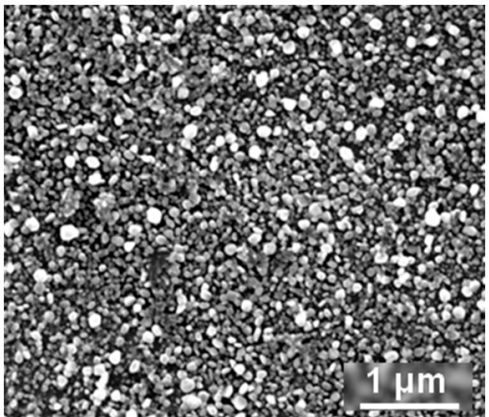

(b)

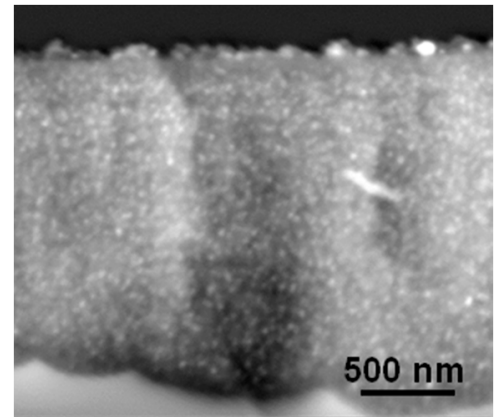

(c)

Figure 6. (a) Top-view SEM image of BSi surface; (b) top-view and (c) cross section SEM images (using backscattering diffusion detector) of $\mu \mathrm{PSi}$ sample after impregnation by a solution of CuMes in $\left[\mathrm{C}_{1} \mathrm{C}_{4} \mathrm{Im}\right]\left[\mathrm{NTf}_{2}\right]$ under argon atmosphere for $2 \mathrm{~h}$ at $50{ }^{\circ} \mathrm{C}$.

\subsection{Generalization to Other Metals}

As highlighted in the introduction, this procedure should be suited to deposit other metals as well. To explore this possibility, this process was applied to solutions of other OM precursors in IL. 


\subsubsection{Palladium}

$\mathrm{BSi}$ and $\mu \mathrm{PSi}$ samples were treated with a solution of $\mathrm{Pd}(\mathrm{dba})_{2}$ in $\left[\mathrm{C}_{1} \mathrm{C}_{4} \operatorname{Im}\right]\left[\mathrm{NTf}_{2}\right]$ for $2 \mathrm{~h}$ at $50{ }^{\circ} \mathrm{C}$ under argon atmosphere. As expected, no Pd deposit was observed on the BSi surface (Figure 7a). By contrast, a population of large Pd islands was present at the surface of $\mu \mathrm{PSi}$ (Figure $7 \mathrm{~b}$ ) and a dense population of Pd-NPs (12 nm in diameter) in the micropores (Figure 7c). These results are thus similar to those obtained with CuMes, indicating that the same mechanisms are at play.

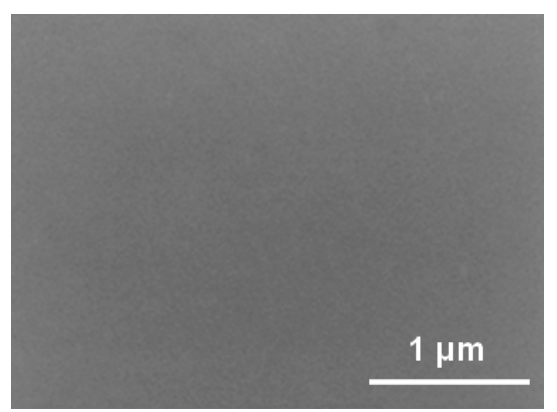

(a)

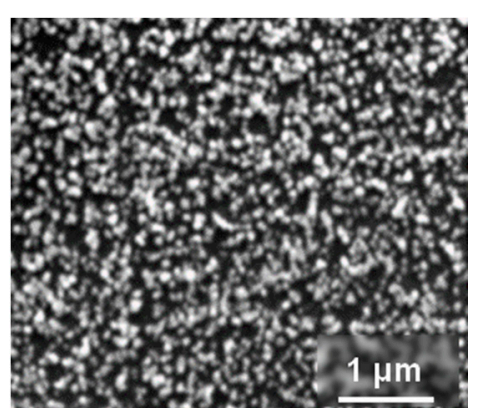

(b)

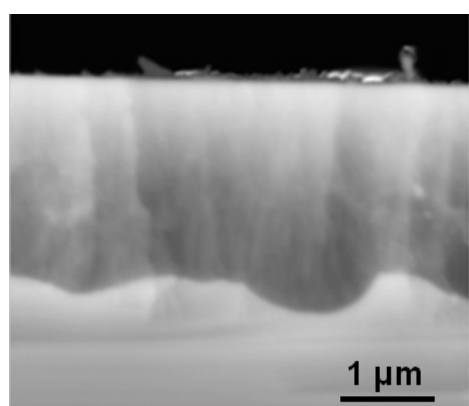

(c)

Figure 7. SEM images after reaction with $\mathrm{Pd}(\mathrm{dba})_{2}$ in $\left[\mathrm{C}_{1} \mathrm{C}_{4} \mathrm{Im}\right]\left[\mathrm{NTf}_{2}\right]$ at $50{ }^{\circ} \mathrm{C}$ under argon atmosphere for 2 h. (a) BSi surface; $\mu$ PSi (b) surface and (c) micropores (cross section).

\subsubsection{Platinum}

With $\mathrm{Pt}(\mathrm{dba})_{2}$ as an OM precursor, no Pt deposit formed on the (BSi) surface (Figure 8a), whereas populations of large Pt islands and small particles were observed on the $\mu \mathrm{PSi}$ surface and in the micropores, respectively (Figure 8b,c). The EDX analysis confirms the presence of Pt with some traces of ILs. Note that the overall amount of deposited $\mathrm{Pt}$ is weaker than for $\mathrm{Pd}$ and $\mathrm{Cu}$. This could be ascribed to (i) the larger size of $\mathrm{Pt}$ particles on the surface ( $\approx 400 \mathrm{~nm} v s . \approx 40 \mathrm{~nm}$ for $\mathrm{Cu}$ and $\mathrm{Pd})$ and (ii) a partial leaching of the Pt-NPs during the rinsing process (the anhydrous $\mathrm{CH}_{2} \mathrm{Cl}_{2}$ went from colorless to red amid rinsing).

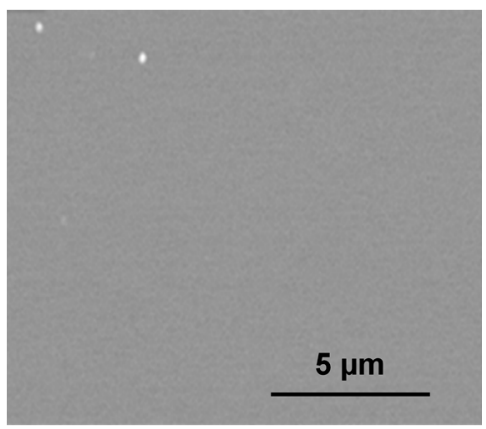

(a)

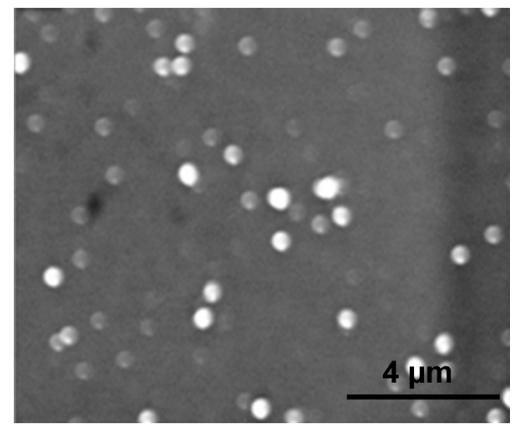

(b)

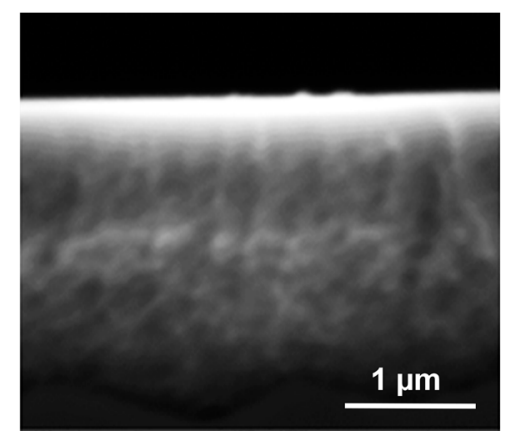

(c)

Figure 8. SEM images after reaction with $\mathrm{Pt}(\mathrm{dba})_{2}$ in $\left[\mathrm{C}_{1} \mathrm{C}_{4} \mathrm{Im}\right]\left[\mathrm{NTf}_{2}\right]$ at $50{ }^{\circ} \mathrm{C}$ under argon atmosphere for $2 \mathrm{~h}$. (a) BSi surface; $\mu \mathrm{PSi}$ (b) surface and (c) micropores (cross section).

To increase Pt content in $\mu \mathrm{PSi}$, the more reactive (COD)Pt(Me $)_{2}$ was tested. With this precursor, the density and size of Pt-NPs were similar to those of $\mathrm{Cu}$ and Pd (Figure 9). However, the metal concentration decreased with depth. As explained with high-temperature experiments with CuMes (see Figure 5), this can be ascribed to an overly fast decomposition of (COD)Pt(Me) $)_{2}$, as compared to the rate of penetration of the precursor into the pores. 


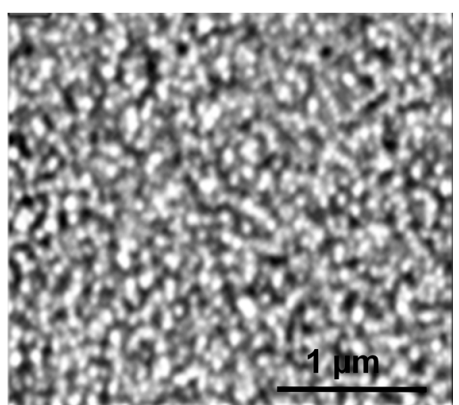

(a)

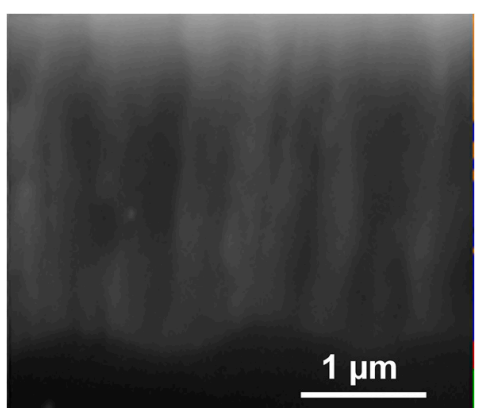

(b)

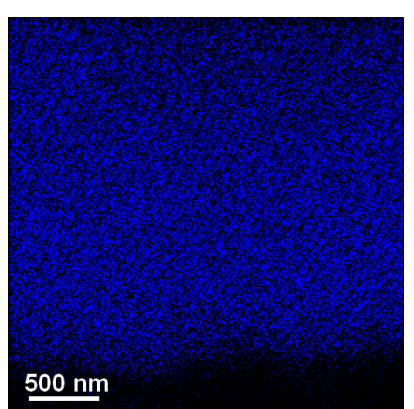

(c)

Figure 9. SEM images of (a) the surface (b) the cross-section of $\mu \mathrm{PSi}$ after reaction with $\mathrm{Pt}(\mathrm{Me})_{2}(\mathrm{COD})$ in $\left[\mathrm{C}_{1} \mathrm{C}_{4} \operatorname{Im}\right]\left[\mathrm{NTf}_{2}\right]$ at $50{ }^{\circ} \mathrm{C}$ under argon atmosphere for $2 \mathrm{~h}$; (c) EDX mapping of Pt in the cross section.

\subsubsection{Ruthenium}

With (COD) $\mathrm{Ru}$ (2-methylallyl) $)_{2}$, it was found that rinsing with $\mathrm{CH}_{2} \mathrm{Cl}_{2}$ resulted in a dark solution. Several successive rinses were needed to obtain a clear solution and properly remove residual IL from the surface. Therefore, in this case, significant leaching of Ru (RuNPs or starting material) occurred. As a result, only sparse particles remained on the $\mu$ PSi surface (Figure 10a). Nevertheless, RuNPs were still present in the pores, as confirmed by SEM and EDX mapping (Figure 10b).

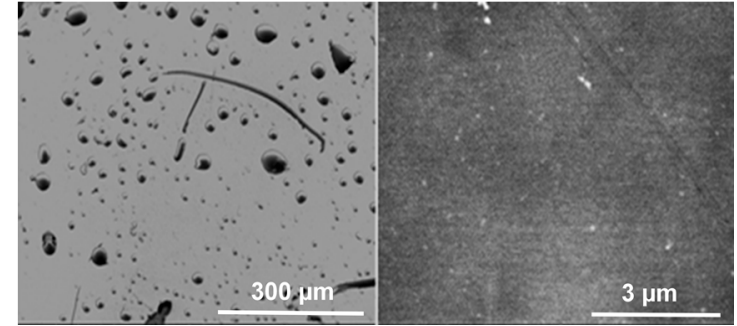

(a)

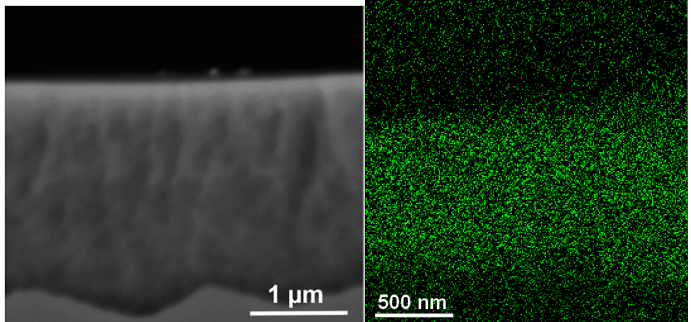

(b)

Figure 10. SEM images of the surface of $\mu \mathrm{PSi}$ after reaction with (COD)Ru(2-methylallyl $)_{2}$ in $\left[\mathrm{C}_{1} \mathrm{C}_{4} \mathrm{Im}\right]\left[\mathrm{NTf}_{2}\right]$ at $50{ }^{\circ} \mathrm{C}$ under argon atmosphere for $2 \mathrm{~h}$ and after washing. (a) Left twice or right five times with $\mathrm{CH}_{2} \mathrm{Cl}_{2} ;(\mathbf{b})$ cross section of $\mu \mathrm{PSi}$ and corresponding EDX mapping of $\mathrm{Ru}$.

\section{Materials and Methods}

All operations were performed in the strict absence of oxygen and water under purified argon atmosphere using glove-box (MBraun) or vacuum-line techniques. Bis(dibenzylideneacetone) platinum, $\mathrm{Pt}(\mathrm{dba})_{2}$, Bis(dibenzylideneacetone)palladium $(0)\left(\mathrm{Pd}(\mathrm{dba})_{2}\right)$ (Strem), (1,5-cyclooctadiene) dimethylplatine(II) $\left(\mathrm{Pt}(\mathrm{Me})_{2}\right.$ (COD)) (Nanomeps), bis(2-methylallyl)(1,5-cyclooctadiene)ruthenium(II) $\left(\mathrm{Ru}(2 \text {-methylallyl })_{2}(\mathrm{COD})\right)$ (Sigma Aldrich, St. Louis, MO, USA) and mesitylcopper (CuMes) (Nanomeps) were kept in a refrigerator in the glove box and used as received.

1-Butyl-3-methylimidazoliumbis(trifluoromethylsulphonyl)imide, $\left[\mathrm{C}_{1} \mathrm{C}_{4} \operatorname{Im}\right]\left[\mathrm{NTf}_{2}\right]$, was prepared as already reported [29]. Its purity was checked via NMR spectra recorded on a Bruker Advance spectrometer at $300 \mathrm{MHz}$ for ${ }^{1} \mathrm{H}$ and at $75.43 \mathrm{MHz}$ for ${ }^{13} \mathrm{C}$. After purification, the halide content was found to be below 100 ppm (HR-SM), and water found to be $\sim 12$ ppm (limit of Karl Fischer titration).

The solutions were freshly prepared by dissolving CuMes in $\left[\mathrm{C}_{1} \mathrm{C}_{4} \operatorname{Im}\right]\left[\mathrm{NTf}_{2}\right]$ to the desired concentration $\left(5 \times 10^{-2}\right.$ mole $\left.\cdot \mathrm{L}^{-1}\right)$ in a Schlenk tube under stirring at room temperature.

Suspensions of $\mathrm{Cu}-\mathrm{NPs}$ were prepared as already reported [24]. The NPs were observed by TEM using a Philips CM120 at $120 \mathrm{kV}$. For this purpose, in the glove box, the suspensions were deposited on a TEM grid and transferred into the microscope without further preparation. For each suspension, the size of at least 200 NPs was measured. Their size distribution was then fitted by a lognormal law. 
Different types of Si surfaces were used-two porous and one non-porous (bulk) surface as a reference. The porous layers were electrochemically generated in a hydrofluoric solution on 200-mm Si wafers using an automated piece of equipment composed of a cleaning and an anodizing chamber.

\section{Conclusions}

An original process for the metallization of porous Si (PSi) materials was investigated here. Ionic liquids were shown to be efficient in impregnating PSi layers and to convey organometallic $(\mathrm{OM})$ precursors at the bottom of the pores. Interestingly enough, microporous $\mathrm{Si}(\mu \mathrm{PSi})$, which is known to reduce metal ions in aqueous solutions, is able to decompose OM precursors in ILs as well. However, this reaction most probably involves the surface hydride groups, in contrast with aqueous media (in which $\mathrm{Si}$ is oxidized). In addition, these groups contribute to the grafting of the metal. The reduction of CuMes by these surface hydride groups is still under investigation. However, it has been successfully generalized to other metals such as $\mathrm{Pt}$, Pd, and $\mathrm{Ru}$. Finally, this approach does not require additional reducing agents; hence, the safety and the cost of the process are improved.

Acknowledgments: Walid Darwich thanks the French Region Rhône-Alpes through the ARC6 Program for the Ph.D. grant.

Author Contributions: Catherine C. Santini and Paul-Henri Haumesser conceived and designed the experiments; Walid Darwich performed the experiments and analyzed the data; Frédéric Gaillard contributed silicon material and silicon chemistry expertise; Walid Darwich, Paul-Henri Haumesser and Catherine C. Santini wrote the paper.

Conflicts of Interest: The authors declare no conflict of interest.

\section{Abbreviations}

$\begin{array}{ll}\mathrm{IL} & \text { ionic liquids } \\ \mathrm{NP} & \text { nanoparticle } \\ {\left[\mathrm{C}_{1} \mathrm{C}_{4} \mathrm{Im}\right]\left[\mathrm{NTf}_{2}\right]} & \text { 1-butyl-3-methylimidazolium bis(trifluoromethylsulphonyl)imide } \\ \mathrm{SEM} & \text { scanning electron microscope } \\ \text { EDX } & \text { energy-dispersive X-ray spectroscopy }\end{array}$

\section{References}

1. Buriak, J.M. Organometallic chemistry on silicon surfaces: Formation of functional monolayers bound through Si-C bonds. Chem. Commun. 1999, 12, 1051-1060. [CrossRef]

2. Granitzer, P.; Rumpf, K. Porous silicon-A versatile host material. Materials 2010, 3, 943-998. [CrossRef]

3. Herino, R. Nanocomposite materials from porous silicon. Mater. Sci. Eng. B Solid State Mater. Adv. Technol. 2000, 69, 70-76. [CrossRef]

4. De la Mora, M.B.; del Río, J.A.; Nava, R.; Tagüeña-Martínez, J.; Reyes-Esqueda, J.A.; Kavokin, A.; Faubert, J.; Lugo, J.E. Anomalous patterned scattering spectra of one-dimensional porous silicon photonic crystals. Opt. Express 2000, 18, 22808-22816. [CrossRef] [PubMed]

5. Bandarenka, H.; Prischepa, S.; Fittipaldi, R.; Vecchione, A.; Nenzi, P.; Balucani, M.; Bondarenko, V. Comparative study of initial stages of copper immersion deposition on bulk and porous silicon. Nanoscale Res. Lett. 2013, 8, 1-8. [CrossRef] [PubMed]

6. Bandarenka, H.; Redko, S.; Smirnov, A.; Panarin, A.; Terekhov, S.; Nenzi, P.; Balucani, M.; Bondarenko, V. Nanostructures formed by displacement of porous silicon with copper: From nanoparticles to porous membranes. Nanoscale Res. Lett. 2012, 7, 1-10. [CrossRef] [PubMed]

7. Tsuboi, T.; Sakka, T.; Ogata, Y.H. Metal deposition into a porous silicon layer by immersion plating: Influence of halogen ions. J. Appl. Phys. 1998, 83, 4501-4506. [CrossRef]

8. Parbukov, A.N.; Beklemyshev, V.I.; Gontar, V.M.; Makhonin, I.I.; Gavrilov, S.A.; Bayliss, S.C. The production of a novel stain-etched porous silicon, metallization of the porous surface and application in hydrocarbon sensors. Mater. Sci. Eng. C Biomim. Supramol. Syst. 2001, 15, 121-123. [CrossRef]

9. Harraz, F.A.; Tsuboi, T.; Sasano, J.; Sakka, T.; Ogata, Y.H. Metal, deposition onto a porous silicon layer by immersion plating from aqueous and nonaqueous solutions. J. Electrochem. Soc. 2002, 149, C456-C463. [CrossRef] 
10. Ogata, Y.H.; Kobayashi, K.; Motoyama, M. Electrochemical metal deposition on silicon. Curr. Opin. Solid State Mater. Sci. 2006, 10, 163-172. [CrossRef]

11. Fukami, K.; Kobayashi, K.; Matsumoto, T.; Kawamura, Y.L.; Sakka, T.; Ogata, Y.H. Electrodeposition of noble metals into ordered macropores in p-type silicon. J. Electrochem. Soc. 2008, 155, 443-448. [CrossRef]

12. Morinaga, H.; Suyama, M.; Ohmi, T. Mechanism of metallic particle growth and metal-induced pitting on Si wafer surface in wet chemical-processing. J. Electrochem. Soc. 1994, 141, 2834-2841. [CrossRef]

13. Aylett, B.J.; Harding, I.S.; Earwaker, L.G.; Forcey, K.; Giaddui, T. Metallisation of porous silicon by chemical vapour infiltration and deposition. Thin Solid Films 1996, 276, 253-256. [CrossRef]

14. Liu, H.; Jiang, L. Wettability by ionic liquids. Small 2016, 12, 9-15. [CrossRef] [PubMed]

15. Dupont, J.; Scholten, J.D. On the structural and surface properties of transition-metal nanoparticles in ionic liquids. Chem. Soc. Rev. 2010, 39, 1780-1804. [CrossRef] [PubMed]

16. Campbell, P.S.; Podgorsek, A.; Gutel, T.; Santini, C.C.; Padua, A.A.H.; Costa, G.M.F.; Bayard, F.; Fenet, B.; Chauvin, Y. How do physical-chemical parameters influence the catalytic hydrogenation of 1,3-cyclohexadiene in ionic liquids? J. Phys. Chem. B 2010, 114, 8156-8165. [CrossRef] [PubMed]

17. Helgadottir, I.; Freychet, G.; Arquilliere, P.; Maret, M.; Gergaud, P.; Haumesser, P.H.; Santini, C.C. $\mathrm{Ru}$-core/Cu-shell bimetallic nanoparticles with controlled size formed in one-pot synthesis. Nanoscale 2014, 6, 14856-14862. [CrossRef] [PubMed]

18. Campbell, P.S.; Prechtl, M.H.G.; Santini, C.C.; Haumesser, P.H. Ruthenium nanoparticles in ionic liquids-A saga. Curr. Org. Chem. 2013, 17, 414-429. [CrossRef]

19. Fonseca, G.S.; Umpierre, A.P.; Fichtner, P.F.P.; Teixeira, S.R.; Dupont, J. The use of imidazolium ionic liquids for the formation and stabilization of Ir0 and Rh0 nanoparticles: Efficient catalysts for the hydrogenation of arenes. Chem. Eur. J. 2003, 9, 3263-3269. [CrossRef] [PubMed]

20. Prechtl, M.H.G.; Campbell, P.S.; Scholten, J.D.; Fraser, G.B.; Machado, G.; Santini, C.C.; Dupont, J.; Chauvin, Y. Imidazolium ionic liquids as promoters and stabilising agents for the preparation of metal( 0 ) nanoparticles by reduction and decomposition of organometallic complexes. Nanoscale 2010, 2, 2601-2606. [CrossRef] [PubMed]

21. Dupont, J.; Meneghetti, M.R. On the stabilization and surface properties of soluble transition-metal nanoparticles in non-functionalized imidazolium-based ionic liquids. Curr. Opin. Colloid Interface Sci. 2013, 18, 54-60. [CrossRef]

22. Podgorsek, A.; Pensado, A.S.; Santini, C.C.; Gomes, M.F.C.; Padua, A.A.H. Interaction energies of ionic liquids with metallic nanoparticles: Solvation and stabilization effects. J. Phys. Chem. C 2013, 117, 3537-3547. [CrossRef]

23. Darwich, W. Thin Metallic Films Deposited from a Suspension of Nanoparticles in Ionic Liquids; Univeristé Claude Bernard Lyon 1: Lyon, France, 2005.

24. Arquillière, P.P.; Haumesser, P.H.; Santini, C.C. Copper nanoparticles generated in situ in imidazolium based ionic liquids. Microelectron. Eng. 2012, 92, 149-151. [CrossRef]

25. Kolasinski, K.W.; Barclay, W.B.; Sun, Y.; Aindow, M. The stoichiometry of metal assisted etching (MAE) of Si in $\mathrm{V}_{2} \mathrm{O}_{5}+\mathrm{HF}$ and $\mathrm{HOOH}+\mathrm{HF}$ solutions. Electrochim. Acta 2015, 158, 219-228. [CrossRef]

26. Sham, T.K.; Coulthard, I.; Lorimer, J.W.; Hiraya, A.; Watanabe, M. Reductive deposition of Cu on porous silicon from aqueous solutions: An X-ray absorion study at the Cu L3,2 Edge. Chem. Mater. 1994, 6, 2085-2091. [CrossRef]

27. Coulthard, I.; Sham, T.K. Morphology of porous silicon layers: Image of active sites from reductive deposition of copper onto the surface. Appl. Surf. Sci. 1998, 126, 287-291. [CrossRef]

28. Kumar, P.; Huber, P. Nucleation and growth of copper on mesoporous silicon by immersion plating. J. Phys. D Appl. Phys. 2007, 40, 2864-2869. [CrossRef]

29. Crowhurst, L.; Lancaster, N.L.; Perez-Arlandis, J.M.; Welton, T. Manipulating solute nucleophilicity with room temperature ionic liquids. J. Am. Chem. Soc. 2004, 126, 11549-11555. [CrossRef] [PubMed]

(C) 2016 by the authors; licensee MDPI, Basel, Switzerland. This article is an open access article distributed under the terms and conditions of the Creative Commons Attribution (CC-BY) license (http:/ / creativecommons.org/licenses/by/4.0/). 